\begin{tabular}{lllllllllllllllllllllllllllllllll}
\hline$R$ & $E$ & $V$ & I & S & T & A & D & E & E & S & T & U & D & I & O & S & I & N & T & E & R & N & A & C & I & O & N & A & L & E & S
\end{tabular}

\title{
La reforma constitucional de 2005 en materia de tratados internacionales
}

\author{
Marisol Peña Torres
}

\begin{abstract}
«Las reformas constitucionales son absolutamente imprescindibles como adaptaciones de la dinámica constitucional a las condiciones sociales en constante cambio; pero cada una de ellas es una intervención, una operación en un organismo viviente, y debe ser solamente efectuada con gran cuidado y extremada reserva» ${ }^{1}$.
\end{abstract}

La reforma constitucional aprobada en el mes de Agosto pasado asumió una serie de vacíos e interrogantes planteados por la redacción de las normas contenidas en el texto original de la Constitución Política en materia de tratados internacionales. Ello, sin duda, ha venido a perfeccionar la Carta Fundamental; no obstante han quedado pendientes una serie de materias indispensables de abordar para lograr la plena inserción de Chile en el mundo globalizado.

\section{INTRODUCCIÓN}

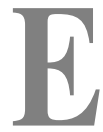

117 de Agosto de 2005, se dio término a la tramitación parlamentaria de la reforma constitucional más completa e integral después de la aprobada en agosto de 1989. Poco más de cinco años demoró la tramitación de la reforma iniciada por la presentación, en el Senado, de dos mociones parlamentarias, la primera presentada en junio del año 2000, por la Alianza por Chile (Boletín No 2526-07) y, la segunda, por la Concertación de Partidos por la Democracia (Boletín No 2534-07).

Las mencionadas mociones parlamentarias fueron objeto de un sinnúmero de

1 Loewenstein, Karl, Teoría de la Constitución, Barcelona, Editorial Ariel, 1982, p. 199. 
indicaciones provenientes tanto del Ejecutivo como de parlamentarios de ambas Cámaras del Congreso Nacional hasta alcanzarse, en octubre del año 2004, un importante acuerdo político entre los partidos políticos de representación parlamentaria y el Ministro del Interior que posibilitó, en definitiva, la pronta aprobación de las reformas.

\section{Los partidos políticos y el ministro del Interior llegaron a un acuerdo que permitió la pronta aprobación de las reformas.}

En el debate sostenido durante el primer trámite constitucional, el Senador Sergio Diez expresaba que:

Las dos mociones presentadas revelan un apreciable grado de coincidencia en importantes materias, como la inclusión dentro de las bases de la institucionalidad de los principios de probidad y transparencia de las actuaciones públicas; la eliminación de la diferencia entre legislatura ordinaria y extraordinaria a fin de reconocer al Congreso Nacional una mayor capacidad de decisión sobre la agenda legislativa; la revisión del papel del Parlamento en cuanto a la aprobación de los tratados internacionales; la conveniencia de revisar la integración del Senado; el aumento de las facultades fiscalizadoras de la Cámara de Diputados; la modificación de la integración del Tribunal Constitucional, y el reforzamiento de las atribuciones de este último, entre otros aspectos ${ }^{2}$.

Como puede apreciarse, ambos conglomerados políticos estuvieron de acuerdo en revisar la normativa constitucional vigente en materia de aprobación de los tratados internacionales con el objeto de reevaluar el rol que cumplía el Congreso Nacional. De allí que resulte pertinente iniciar el examen de la reforma constitucional del 2005, en materia de tratados internacionales sintetizando, brevemente, la normativa original de la Constitución de 1980 sobre el particular.

La regulación contenida en el texto original de la Constitución de 1980 respecto de los tratados internacionales

Partiendo de la base de que un tratado internacional es «un acuerdo internacional celebrado por escrito entre Estados y regido por el derecho internacional, ya conste en un instrumento único o en dos o más instrumentos conexos y cualquiera que sea su denominación particular» ${ }^{3}$, el texto original de la Constitución Política, disponía:

1. La obligación de todos los órganos del Estado de respetar y promover los derechos esenciales de la persona consagrados tanto en la Constitución Política como en los tratados internacionales ratificados por Chile y que se encuentren vi-

2 Senado de la República, Informe de la Comisión de Constitución, Legislación, Justicia y Reglamento, Reforma a la Constitución Política de la República de 1980, noviembre de 2001, p. 16.

3 Convención de Viena sobre el Derecho de los Tratados, Art. 2.1 letra a). 
gentes (Art. $5^{\circ}$ inciso $2^{\circ}$ reformado en agosto de 1989 por Ley $\mathrm{N}^{\circ} 18.825$ ).

\section{Los derechos que la Constitución} asegura a todas las personas se complementan y amplían con aquellos reconocidos en tratados internacionales vigentes en Chile.

En virtud de dicha norma, el respeto de los derechos esenciales derivados de la naturaleza humana no sólo se entendía como un límite al ejercicio de la soberanía sino como un deber de los órganos del Estado, al cual se agregaba el de «promover» tales derechos removiendo los obstáculos que impidiesen su libre ejercicio. Al mismo tiempo, dejaba en claro que el catálogo de derechos asegurados a todas las personas en nuestro país no se agotaba en aquellos enunciados en el Art. 19 de la Carta Fundamental, sino que se complementaba y ampliaba con los demás derechos reconocidos por tratados internacionales ${ }^{4}$ que Chile hubiese ratificado y que se encontraron vigentes.

2. La potestad del presidente de la República de «conducir las relaciones políticas con las potencias extranjeras y organismos internacionales, y llevar a cabo las negociaciones», así como de «concluir, firmar y ratificar los tratados que estime convenientes para los intereses del país» (Art. $32 \mathrm{~N}^{\circ} 17$ ).
Sobre esta potestad, la ministra de Relaciones Exteriores, Soledad Alvear, recordaba, en el curso del debate de la reforma constitucional, que «desde el inicio de la historia republicana, nuestro país, de tradición presidencialista, le confía a este la mantención de las relaciones políticas, la conducción de las negociaciones y la conclusión, firma y ratificación de los tratados, asignándole al Parlamento la tarea de su aprobación antes de la ratificación» ${ }^{5}$.

3. Los tratados internacionales debían ser sometidos a la aprobación del Congreso Nacional antes de su ratificación (Art. $50 \mathrm{~N}^{\circ} 1$ inciso $1^{\circ}$ ). El Congreso sólo podía aceptarlos o rechazarlos y, para esos efectos, debían sujetarse a los trámites de una ley.

4. No era necesaria nueva aprobación del Congreso para la adopción de medidas o de acuerdos que celebrara el presidente de la República en cumplimiento de un tratado en vigor, a menos que se tratara de materias propias de ley (Art. $50 \mathrm{~N}^{\circ} 1$ ) inciso $2^{\circ}$ ).

Esta norma se refería a los executive agreements o «acuerdos en forma simplificada», como los que suelen convenirse para efectos de la visación de pasaportes o del transporte de valijas diplomáticas.

En la Comisión de Estudios de la Nueva Constitución Política se dejó constancia de que se trataba de introducir en el texto constitucional la innovación previa-

4 Este es el caso del derecho al nombre (Art. 18 de la Convención Americana sobre Derechos Humanos), del derecho a la nacionalidad (Art. 20 de la misma Convención) y del derecho a fundar una familia (Art. 23 del Pacto Internacional de Derechos Civiles y Políticos), entre otros.

5 Senado de la República, Informe de la Comisión de Constitución, Legislación, Justicia y Reglamento, Reforma a la Constitución Política de la República de 1980, noviembre de 2001, p. 323. 
mente consagrada por el D.L. $247^{6}$. En la misma Comisión se aclaró la diferencia entre los tratados «marco», que requerían necesariamente de la aprobación de un órgano político, y los tratados «de ejecución» respecto de los cuales dicha aprobación no era necesaria ${ }^{7}$. Se desechó, sin embargo, una alternativa como la contenida en la Constitución Francesa de 1958 (Art. 53), que señala explícitamente cuáles son los tratados que deben ser aprobados por ley (de paz, comercio, relativos a organizaciones internacionales o que incidan en las finanzas del Estado, los que modifiquen disposiciones legislativas, los relativos al estado de las personas y los que entrañen cesión, canje o accesión de territorio).

\section{La Comisión de Estudios aclaró} la diferencia entre tratados que requieren aprobación de un órgano político y aquellos en que no es necesaria.

5. En el mismo acuerdo aprobatorio de un tratado, el Congreso podrá autorizar al presidente de la República para que, durante su vigencia, dicte aquellas disposiciones con fuerza de ley que estimara necesarias para su cabal cumplimiento
(Art. $50 \mathrm{~N}^{\circ} 1$ inciso $3^{\circ}$ ). En este caso, la norma jurídica que dictara el presidente de la República sería propiamente un decreto con fuerza de ley sometido a los límites señalados en el Art. 61 de la Constitución Política.

6. Podía promoverse una «cuestión de constitucionalidad», ante el Tribunal Constitucional respecto de los tratados que se encontraran sometidos a la aprobación del Congreso Nacional (Art. $\left.82 \mathrm{~N}^{\circ} 2\right)^{8}$.

\section{Problemas y vacíos de la regulación constitucional anterior}

Sintetizada la normativa constitucional anterior a la reforma, es necesario examinar qué problemas o vacíos presentó su aplicación, a fin de determinar si la reforma efectivamente se hizo cargo de darles solución. Así, podríamos sostener que los principales problemas derivados de la redacción de las normas originales de la Constitución de 1980, en materia de tratados internacionales, fueron:

1. Las facultades prácticamente omnímodas del presidente de la República para que el país asumiera obligaciones derivadas de tratados internacionales, si se tiene presente que el Congreso Nacional solamente podía aprobar o rechazar el

6 Actas Oficiales de la Comisión de la Comisión de Estudios de la Nueva Constitución Política, Sesión 64, del 3 de mayo de 1978, p. 2452.

7 Actas Oficiales de la Comisión de Estudios de la Nueva Constitución Política, Sesión 367, del 9 de mayo de 1978, p. 2499.

8 Sobre el alcance de esta atribución del Tribunal Constitucional puede consultarse su Resolución Rol $\mathrm{N}^{\circ}$ 288, de 24 de junio de 1999, que se refiere al Acuerdo entre las repúblicas de Chile y de Argentina para precisar el recorrido del límite desde el Monte Fitz Roy hasta el Cerro Daudet (especialmente, el considerando $15^{\circ}$ ). 
tratado, pero no podía modificarlo ni menos formular reservas.

Sobre el particular, durante la discusión parlamentaria de la reforma constitucional del 2005, el distinguido profesor Santiago Benadava expresó que en términos generales, no es partidario de establecer cortapisas a la acción presidencial en materia de celebración de tratados, pero que no obstante había observado que «en las Constituciones de ciertas naciones existen limitaciones en cuanto a la conclusión de convenios que afecten la integridad territorial del Estado; es el caso de España en lo referido a tratados internacionales que disponen arreglos que importen variaciones, cesiones, cambios o agregaciones de territorio». Agregaba que «la Constitución de El Salvador proscribe la celebración o ratificación de tratados que de alguna manera menoscaben la integridad del territorio, la soberanía o independencia de la República»?

Por su parte, es preciso indicar que en la Comisión de Estudios de la Nueva Constitución Política se hizo presente la necesidad de que las facultades indiscutibles que tiene el presidente de la República en materia de política exterior fueran matizadas, en el caso de la aprobación de los tratados, atendida la importancia que reviste para el Estado la adquisición de obligaciones en virtud de estos. Fue así como en los debates de la referida Comisión se consideró la idea de que, entre los temas que podían motivar una convocatoria a plebiscito -aunque facultativo-estuvieran las materias internacionales (tales como la cesión o canje de territorios) mediante convocatoria del presidente de la República con acuerdo del Senado ${ }^{10}$.

\section{Someter la aprobación de ciertos tratados a plebiscito podía constituir un elemento de presión.}

No obstante, en el curso de ese mismo debate el comisionado Jaime Guzmán manifestó sus aprensiones en este sentido, aduciendo que la sola posibilidad de someter la aprobación de ciertos tratados internacionales a plebiscito «podría constituir un elemento de presión no fácil de eludir por parte del presidente de la República y del Senado ${ }^{11}$. Proponía, en cambio, exigir un quórum más alto para la aprobación de tratados cuya naturaleza se estimase grave para los destinos del país ${ }^{12}$.

Consecuente con la idea mayoritaria de la Comisión de Estudios de la Nueva Constitución Política, el Anteproyecto emanado de esta contempló la facultad del presidente de la República de convocar a plebiscito para efectos de la aprobación o rechazo de tratados internacionales (Art. 37 $\mathrm{N}^{\circ} 4$ ), proposición que fue eliminada en el Anteproyecto del Consejo de Estado.

Con todo, y respecto de la naturaleza y alcances de la atribución presidencial en

9 Senado de la República, Informe de la Comisión de Constitución, Legislación, Justicia y Reglamento, Reforma a la Constitución Política de la República de 1980, noviembre de 2001, p. 337.

10 Actas Oficiales de la Comisión de Estudios de la Nueva Constitución Política, Sesión 364, 3 de mayo de 1978, p. 2454.

11 Op. cit., p. 2455. 
materia de tratados internacionales, el Tribunal Constitucional ha estimado que la potestad contenida en el Art. $32 \mathrm{~N}^{\mathrm{o}} 17 \mathrm{de}$ la Constitución Política es «exclusiva y excluyente», correspondiendo al Congreso Nacional sólo la aprobación o rechazo del tratado antes de su ratificación. ${ }^{13}$ En idéntica forma se ha pronunciado sobre la facultad del presidente de la República de ratificar los tratados internacionales, señalando que es una facultad «discrecional no sujeta a plazo». ${ }^{14}$

Asimismo, ha expresado que los tratados «deben aprobarse o desecharse como un todo sin que sea admisible que el Parlamento les introduzca modificaciones» ${ }^{15}$.

De allí que, en la práctica, ha ocurrido que cuando el Congreso estima que un tratado debe ratificarse con reservas por parte de Chile, así lo ha sugerido al presidente de la República, en el mismo oficio en que comunica el acuerdo aprobatorio del tratado respectivo ${ }^{16}$.

2. Las interrogantes surgidas en torno a la formalidad para aprobar los tratados, ya que la mención del Art. $50 \mathrm{~N}^{\circ} 1$ en el sentido de que la aprobación de los tratados «se someterá a los trámites de una ley» es genérica, en circunstancia de que existen distintos tipos de normas legales según la materia en que estas recaen (Art. 63 de la Constitución Política). En el debate de la Comisión de la Comisión de Estudios de la nueva Carta, su presidente Enrique Ortúzar Escobar, ya había manifestado que la idea de someter los tratados «a los mismos trámites de una ley» podía prestarse para interpretaciones equívocas ${ }^{17}$.

\section{Se sostuvo que someter los tratados «a los mismos trámites de una ley» podía prestarse para interpretaciones equívocas.}

Al precisar la última frase del Art. 50 $\mathrm{N}^{\circ} 1$ inciso $1^{\circ}-\ll$ deben someterse a los trámites de una ley»- el Tribunal Constitucional, había tenido oportunidad de precisar que ello implica que, en la aprobación, no solo deben observarse los pasos o etapas requeridos en la formación de las normas legales sino también los quórum exigidos para aprobarlas que son consustanciales a los trámites de formación de la misma, por ejemplo, si se trata de ma-

12 Op. cit., p. 2458.

13 Rol No 379 , de $1^{\circ}$ de julio de 2003, recaído en el Proyecto de Ley que crea el Consejo Nacional de la Cultura y las Artes y el Fondo Nacional de Desarrollo Cultural y las Artes, considerando $39^{\circ}$.

14 Rol No 288, de 24 de junio de 1999, recaído en el Acuerdo entre la República de Chile y la República de Argentina para precisar el recorrido del límite entre el Monte Fitz Roy y el Cerro Daudet, considerando $10^{\circ}$.

15 Rol N$^{\circ} 309$, de 4 de agosto de 2001, referido al Convenio $N^{\circ} 169$ de la OIT sobre Pueblos Indígenas y tribales en países independientes, considerando $11^{\circ}$.

16 Gamboa Serráis, Fernando, «La reserva de los tratados en Chile y la participación parlamentaria», Revista Ius et Praxis, Facultad de Ciencias Jurídicas y Sociales Universidad de Talca, Año 7, N² 2001, p. 464.

17 Actas Oficiales de la Comisión Constituyente, Sesión 364, 3 de mayo de 1978, p. 2453. 
terias de ley orgánica constitucional o de ley de quórum calificado ${ }^{18}$.

\section{El rango jerárquico de los tratados internacionales sobre derechos humanos fue objeto de tres interpretaciones diferentes.}

3. Las discrepancias de opiniones entre la Cancillería y la Contraloría General de la República sobre la celebración de tratados en el solo ejercicio de la potestad reglamentaria del presidente de la República y que, por lo mismo, no tengan por referencia una ley o tratado anterior. La tesis de la Contraloría se mostró tradicionalmente limitativa de la potestad presidencial, exigiendo la aprobación del Congreso Nacional. Sobre el particular, la canciller chilena, María Soledad Alvear, manifestaba, en el seno de la Comisión de Constitución, Legislación, Justicia y Reglamento del Senado que «respecto de aquellos (tratados) que se pactan dentro del ejercicio de las facultades privativas del Primer Mandatario, sin extenderse a aspectos que son materias de ley (la
Contraloría) los aceptó en la práctica en muchas ocasiones, aun cuando no los admitió desde el punto de vista teórico» ${ }^{19}$.

4. Las dudas surgidas en torno al rango jerárquico de los tratados internacionales de derechos humanos a partir de la reforma constitucional de agosto de 1989.

Como es de público conocimiento, desde la vigencia de la Reforma Constitucional de agosto de 1989, materializada mediante de la Ley $\mathrm{N}^{\mathrm{o}} 18.825$, surgieron a lo menos tres tipos de interpretaciones diferentes en torno al rango jerárquico de los tratados internacionales sobre derechos humanos:

a) La que sostenía que dicha reforma consagró el rango constitucional de estos tratados estableciendo, al mismo tiempo, un procedimiento secundario de reforma de la Constitución Política ${ }^{20}$.

b) La que planteaba que estos tratados ocupaban un rango intermedio entre la ley común y la Constitución, estando, en todo caso, supeditados a esta ${ }^{21}$.

c) La que predicaba el rango simplemente legal de tales tratados, aunque distinguiendo los derechos contenidos y consagrados en ellos que sí tenían rango constitucional $^{22}$.

18 Rol N$^{\circ} 288$, de 28 de febrero de 1999, referido al Acuerdo entre la República de Chile y la República de Argentina para precisar el recorrido del límite desde el Monte Fitz Roy hasta el Cerro Daudet. Considerandos 13,17 y 18 .

19 Senado de la República, Informe de la Comisión de Constitución, Legislación, Justicia y Reglamento, Reforma a la Constitución Política de la República de 1980, noviembre de 2001, p. 325.

20 Nogueira Alcalá Humberto, «El artículo $5^{\circ}$ de la Constitución y la jerarquía normativa de los tratados internacionales de derechos humanos», ponencia presentada en las Jornadas de Derecho Público, octubre de 1991; y Medina Quiroga Cecilia, Constitución, tratados y derechos esenciales, Corporación Nacional de Reparación y Reconciliación, Santiago, 1993.

21 Bertelsen Repetto Raúl, «Rango jurídico de los tratados internacionales en el derecho chileno», Revista Chilena de Derecho, Vol. 23, Nos. 2 y 3, Tomo I, pp. 211-222.

22 Troncoso Repetto, Claudio y Tomás Vial Solar, «Sobre los derechos humanos reconocidos en tratados internacionales y en la Constitución», Revista Chilena de Derecho, Vol. 20, Nºs. 2 y 3, Tomo II, 
El Tribunal Constitucional ha señalado en reiteradas oportunidades que el tratado y la ley son fuentes de derecho diferentes $^{23}$.

\section{El Tribunal Constitucional ha señalado reiteradamente que el tratado y la ley son fuentes de derecho diferentes.}

En lo que se refiere a su jerarquía, el Tribunal Constitucional, en su resolución de 8 de abril de 2002, sobre el Estatuto de Roma que crea la Corte Penal Internacional, vino a zanjar las discrepancias interpretativas sobre esta materia haciendo suya la opinión del profesor Alejandro Silva Bascuñan, según la cual los tratados prevalecerían sobre la ley cuando se refieren a los derechos de los gobernados o al «estatuto de la libertad», pero que, en todo caso, «constituyen una jerarquía de normas que están por debajo de la Constitución $»^{24}$.

5. La inexistencia de disposiciones constitucionales que permitan delegar competencias en entidades supranacionales, como quedó evidenciado al impedirse la ratificación del Estatuto de Roma por el Tribunal Constitucional si no mediaba previa reforma constitucional. En efecto, en dicha ocasión, el Tribunal expresó: ...este criterio que implica que una jurisdicción supranacional como la Corte Penal Internacional no pueda integrarse al ordenamiento jurídico nacional, frente a los claros términos de nuestra Constitución y sin entrar al mérito del Tratado, no significa que frente a los crímenes atroces que presenció la humanidad en el siglo XX, se acepte la impunidad. Por el contrario, el mundo ve hoy la necesidad de enjuiciar y sancionar en su caso, esos delitos, pero una jurisdicción de carácter supranacional debe insertarse dentro del sistema constitucional nacional procediendo previamente a modificar el texto de la Constitución ${ }^{25}$.

Contenido de la reforma constitucional de 2005 en materia de tratados internacionales.

Como quedará en evidencia al analizarse cada una de las modificaciones que la reforma recientemente promulgada introduce a la Carta Fundamental, se ha procurado dar respuesta a aquellos vacíos e interrogantes que suscitó la aplicación del Art. $50 \mathrm{~N}^{\circ} 1$ de la Constitución, en su versión original. No obstante, un diagnóstico objetivo de la reforma necesariamente debe concluir que subsisten temas pendientes, tanto respecto de aquellos que ya se habían manifestado, a partir de 1981, cuanto de otros relacionados con la adecuada inserción de nuestro país en el mundo globalizado que nos caracteriza.

mayo-diciembre 1993, pp. 695-704, y Fernández González, Miguel Ángel, La reforma al artículo $5^{\circ}$ de la Constitución, Revista Chilena de Derecho, Vol. 16, 1989, pp. 809-825.

$23 \operatorname{Rol~N}^{\circ} 288$, considerando $6^{\circ}$.

24 Rol No 346, de 8 de abril de 2002, recaído en el requerimiento de constitucionalidad contra el Estatuto de Roma que crea la Corte Penal Internacional, considerando 75.

25 Rol No 346, op. cit., considerando 92. 
A continuación se sintetizan las modificaciones introducidas a la normativa constitucional referida a los tratados internacionales:

1. La reforma se hace cargo de aclarar que la aprobación de un tratado requerirá, en cada Cámara, de los quórum que corresponda, de conformidad con el Art. 63 de la Constitución y que se someterá, en lo pertinente, a los trámites de una ley (Art. $50 \mathrm{~N}^{\mathrm{o}} 1$ inciso $1^{\circ}$ ). Asimismo, y en virtud de una disposición transitoria, se declara que los tratados aprobados por el Congreso con anterioridad a la entrada en vigor de la reforma que versen sobre ese tipo de materias, han cumplido el respectivo requisito de quórum, tal como lo precisó el veto presidencial (Disp. Trans. $44^{\mathrm{a}}$ ).

Se acoge así la sugerencia formulada, en este sentido, por el Tribunal Constitucional y que había significado que, en la práctica, las Cámaras del Congreso Nacional distinguieran entre los diversos órdenes de materias contenidos en un tratado internacional a fin de aprobarlas de conformidad con los quórum que la Constitución Política exige en cada caso. Puede sostenerse, entonces, que en esta materia se había producido una verdadera «mutación constitucional» ${ }^{26}$, esto es, un cambio en la interpretación y aplicación de la norma del Art. $50 \mathrm{~N}^{\circ} 1$ en lo referente a la aprobación de los tratados internacionales, la que sin duda vino a cons- tituir el fundamento de la reciente reforma a la Carta Fundamental.

Pensamos que con esta reforma se mantiene la unidad del sistema de fuentes del derecho chileno.

\section{En la práctica, las Cámaras han distinguido entre las distintas} materias a que se refiere un tratado a
fin de someterlas a los quórum que
exigido en la Constitución.

Por lo demás, hay que aplaudir que la reforma haya precisado que «en lo pertinente» los tratados se someterán a los trámites de una ley, ya que, en efecto, hay formalidades aplicables al proceso de formación de estas que no caben respecto de los tratados. Así ocurre con la formación de comisiones mixtas, el régimen de insistencias y los vetos, tal como fue visualizado en la propia Comisión de Estudios de la Nueva Constitución Política. ${ }^{27}$

2. Se incorporan disposiciones referidas a reservas:

De conformidad con la Convención de Viena sobre el Derecho de los Tratados, de 1969, una reserva es «una declaración unilateral, cualquiera que sea su enunciado o denominación, hecha por un Estado al firmar, ratificar, aceptar o aprobar un tratado o al adherirse a él, con objeto de

26 Karl Loewenstein señala que «en la mutación constitucional... (...) se produce una transformación en la realidad de la configuración del poder político, de la estructura social o del equilibrio de intereses, sin que quede actualizada dicha transformación en el documento constitucional: el texto de la constitución permanece intacto», op. cit., p. 165.

27 Actas Oficiales de la Comisión de Estudios de la Nueva Constitución Política, Sesión 364, 3 de mayo de 1978, p. 2453. Intervención del comisionado Juan de Dios Carmona. 
excluir o modificar los efectos jurídicos de ciertas disposiciones del tratado en su aplicación a ese Estado» (Art. 2.1 letra d)).

Las modificaciones introducidas por la reforma en esta materia son las siguientes:

a) El presidente debe informar al Congreso sobre el contenido y alcances del tratado, así como de las reservas que pretenda confirmar o formularle (Art. $50 \mathrm{~N}^{\circ}$ inciso $2^{\circ}$ ).

\section{Al tramitar la aprobación de un tratado, el Congreso puede sugerir reservas y formular declaraciones interpretativas.}

b) Se faculta al Congreso para sugerir la formulación de reservas y declaraciones interpretativas a un tratado internacional en el curso del trámite de su aprobación, siempre que ellas procedan de conformidad con lo previsto en el propio tratado o en las normas generales de derecho internacional (Art. $50 \mathrm{~N}^{\circ} 1$ inciso $3^{\circ}$ ).

c) El retiro de una reserva que haya formulado el presidente de la República y que tuvo en consideración el Congreso Nacional al momento de aprobar el tratado requerirá previo acuerdo de este, de conformidad con lo establecido en la ley orgánica constitucional respectiva. Para estos efectos, el Congreso dispone de un plazo de 30 días para pronunciarse, al cabo del cual, si no hay pronunciamiento, se entenderá aprobado el retiro de la reserva (Art. $50 \mathrm{~N}^{\mathrm{o}} 1$ inciso $8^{\circ}$ ).
Es sabido que la participación del Congreso en la dinámica de las reservas a un tratado enfrenta dos tipos de posiciones: a) La aristocrática, identificada con la libertad absoluta del Gobierno en este sentido y b) la democrática, que posibilita la participación de las Cámaras legislativas ${ }^{28}$. El Reglamento del Congreso Español, por ejemplo, se inclina por esta última posición.

La participación del Congreso en la formulación de reservas nos parece congruente con la idea de un Estado de derecho democrático en que el órgano legislativo es un contrapeso efectivo a las potestades presidenciales. Este contrapeso se debilita cuando se trata de informar reservas que el presidente pretenda confirmar o que ya haya formulado al momento de firmar el tratado.

Por lo demás, facultar al Congreso para sugerir reservas viene a dar expresión constitucional a la práctica previa en esta materia sin alterar mayormente la facultad presidencial, ya que «sugerir», de acuerdo con el Diccionario de la Real Academia de la Lengua Española, significa «hacer entrar en el ánimo alguna idea, insinuarla, inspirarla o hacer caer en ella». Habría sido deseable facultar al Congreso para aprobar o rechazar tanto el tratado como las reservas que el presidente pretenda formularle en forma similar a la solución española ${ }^{29}$.

Por lo tanto, se mantienen casi inalteradas las fuertes facultades presidenciales en esta materia y solo se faculta al 
Congreso para entregar su acuerdo sobre el retiro de reservas que haya tenido en consideración al aprobar el tratado y que, por ende, han obligado al Estado bajo determinada modalidad.

3. Celebración de tratados en el solo ejercicio de la potestad reglamentaria del presidente de la República.

Sobre esta materia, la reforma mantiene la frase según la cual «las medidas que el Presidente de la República adopte o los acuerdos que celebre para el cumplimiento de un tratado en vigor, no requerirán de nueva aprobación del Congreso, a menos que se trate de materias propias de ley». Pero agrega: «No requerirán de aprobación del Congreso los tratados celebrados por el Presidente de la República en el ejercicio de su potestad reglamentaria» (Art. $50 \mathrm{~N}^{\mathrm{o}} 1$ inciso $4^{\circ}$ ).

Se trata de diferenciar esta última situación de la de aquellos tratados celebrados en ejecución de una ley o de un tratado anterior. Sobre aquellos tratados que no tengan por referencia una ley o un tratado anterior, como se dijo, ha habido discrepancias entre la Cancillería y la Contraloría General de la República que estima que sí requieren aprobación del Congreso aun cuado se trate de materias de orden administrativo (aduaneras, tributarias o de transporte) que favorecen una administración más eficiente y expedita.

Si bien la reforma contribuye a aclarar una duda interpretativa surgida durante la vigencia de la normativa constitucional precedente, pensamos que, igualmente, se mantiene una gran incógnita respecto de cuáles son las materias internacionales que solo deben ser reguladas a través de la potestad reglamentaria del presidente sin pasar por la aprobación del Congreso.

\section{Se distingue entre los tratados} celebrados en el ejercicio de la potestad reglamentaria del presidente y los celebrados en ejecución de una ley o tratado anterior.

Creemos que la importancia de resguardar el principio de supremacía constitucional, sobre todo cuando se ejerce la potestad reglamentaria autónoma, merece prestar especial cuidado a la forma en que haya de aplicarse esta nueva disposición, pues no podemos olvidar los diversos conflictos que se han suscitado, bajo la vigencia de esta Carta Fundamental, entre la ley y la potestad reglamentaria autónoma del presidente de la República ${ }^{30}$.

4. Derogación, modificación o suspensión de tratados.

La reforma introduce una norma según la cual «las disposiciones de un tratado solo podrán ser derogadas, modificadas o suspendidas en la forma prevista en los propios tratados o de acuerdo a las normas generales de Derecho internacional» (Art. $50 \mathrm{~N}^{\circ} 1$ inciso $5^{\circ}$ ).

$30 \mathrm{Al}$ respecto pueden consultarse los Roles $\mathrm{N}^{\mathrm{o}} \mathrm{s}$. 146, de 21 de abril de 1992, sobre el decreto que reglamenta la instalación de publicidad caminera (Publicidad Caminera I); 167, de 6 de abril de 1993, sobre la misma materia (Publicidad Caminera II) y 325, de 26 de junio de 2001, sobre el decreto que amplió la restricción de circulación a los vehículos con convertidor catalítico. 
Como señala el profesor Santiago Benadava, «es un principio fundamental de derecho internacional que un tratado en vigor es obligatorio para las partes contratantes y debe ser cumplido por ellas de buena fe. El principio pacta sunt servanda (lo pactado obliga) es la norma más importante del derecho internacional». Agrega que «un Estado no puede invocar su legislación ni las deficiencias de ella para dejar de cumplir las obligaciones que le impone un tratado. Es el orden jurídico interno el que debe adaptarse el tratado y no el tratado al orden jurídico interno ${ }^{31}$.

\section{La nueva norma concilia mejor el derecho interno con las disposiciones de la Convención de Viena sobre Derecho de los Tratados.}

Así, la disposición del nuevo inciso $5^{\circ}$ del Art. $50 \mathrm{~N}^{\circ} 1$ de la Constitución concilia, en mejores términos, nuestro derecho interno con lo previsto en los Arts. 26, 27 y 42 de la Convención de Viena sobre el Derecho de los Tratados de $1969^{32}$.

Por lo demás, una disposición casi idéntica a la recientemente introducida a nuestra Carta Fundamental se contiene en la Constitución española (Art. 96.1) mientras que en El Salvador se prohíbe a la ley modificar o derogar lo acordado en un tratado (Art. 144).

5. Denuncia o retiro de un tratado.

En virtud de la reforma:

a) El Presidente de la República tiene la facultad exclusiva para denunciar un tratado o retirarse de él, para lo cual debe pedir la opinión de ambas Cámaras del Congreso, en el caso de tratados aprobados por éste (que no sean acuerdos de forma simplificada como lo aclaró el veto presidencial). Materializada la denuncia o el retiro deberá informar de ello al Congreso dentro de un plazo de quince días. (Art. $50 \mathrm{~N}^{\circ} 1$ incisos $6^{\circ}$ y $7^{\circ}$ )

b) Una vez que la denuncia o el retiro produzcan sus efectos de conformidad con lo establecido en el tratado internacional, este dejará de tener efecto en el orden jurídico chileno (Art. $50 \mathrm{~N}^{\circ} 1$ inciso $6^{\circ}$ ).

Respecto de estas modificaciones, cabe señalar que dado que la denuncia o retiro implica la voluntad del Estado de no seguir obligado por el tratado, debiera contemplarse la participación del Congreso en forma similar a la que se planteó para efectos de su aprobación. Naturalmente, pedir la mera «opinión» de ambas Cámaras del Congreso -sin carácter vinculanteproduce una disparidad en la intervención de este órgano en la aprobación y en la denuncia o retiro del tratado, respectiva-

31 Benadava, Santiago, Derecho Internacional Público, Santiago, Editorial Jurídica Conosur, 1997, p. 49. buena fe». El Art. 27 precisa que «una parte no podrá invocar las disposiciones de su derecho interno como justificación del incumplimiento de un tratado. Esta norma se entenderá sin perjuicio de los dispuesto en el Art. 46». El Art. 42 señala, en su N² 2, que «la terminación de un tratado, su denuncia o el retiro de una parte no podrán tener lugar sino como resultado de la aplicación de las disposiciones del tratado o de la presente Convención. La misma norma se aplicará a la suspensión de la aplicación de un tratado». 
mente. En otras palabras, debiera aplicarse el principio según el cual «donde la misma razón, la misma disposición».

Así, por lo demás, lo contempla en la Constitución española (Art. 96.2). En la Constitución peruana, por su parte, existe una norma según la cual se requiere también previa aprobación del Congreso (no bastando la sola opinión) cuando la denuncia o retiro incide en tratados sujetos a aprobación de este. En los restantes casos, el presidente de la República tiene la potestad de denunciarlos libremente solo dando cuenta de ello al Congreso (Art. 57).

Debe recordarse, por su parte, que en el curso del debate parlamentario referido a la reforma constitucional que se comenta, el profesor Eduardo Vio, ex Director Jurídico de la Cancillería, hacía ver la conveniencia de que el Ejecutivo comunicara al Congreso Nacional los «hechos esenciales» que se produzcan en relación con la tramitación de tratados no sujetos a la aprobación del Parlamento, a fin de que puedan hacerse efectivas las responsabilidades políticas y los respectivos controles antes de que estos entren en vigor ${ }^{33}$.

En lo que se refiere a la norma sobre el efecto de la denuncia o retiro en el plano internacional, que se estima suficiente para dejar sin efecto el tratado en el plano interno, cabe manifestar algunas aprensiones. En efecto, si el tratado se aprobó conforme a los trámites de una ley, poniéndose en vigencia mediante la publicación del decreto supremo promulgatorio en el Diario Oficial, parece más aconsejable -por razones de certeza jurídica, sobre todo, respecto de los particulares- haber seguido el mismo procedimiento ante el evento de la denuncia o retiro de este.

\section{Por razones de certeza jurídica, habría convenido exigir la publicación del retiro o denuncia de un tratado en el Diario Oficial.}

6. Publicidad de hechos relativos a tratados.

Esta modificación tiende a paliar, de alguna manera, la falta de certeza que produce la disposición previamente comentada, ya que se dispone que «de conformidad a lo establecido en la ley, deberá darse debida publicidad a hechos que digan relación con el tratado internacional, tales como su entrada en vigor, la formulación y retiro de reservas, las declaraciones interpretativas, las objeciones a una reserva y su retiro, la denuncia del tratado, el retiro, la suspensión, la terminación y la nulidad del mismo» (Art. $50 \mathrm{~N}^{\circ} 1$ inciso $9^{\circ}$ ).

Se trata de una disposición interesante, si se considera que son distintos los tiempos y procedimientos que marcan la entrada en vigor de un tratado en el plano internacional y en el plano interno, respectivamente.

Por lo tanto, la plena aplicabilidad de esta disposición queda supeditada a la dictación de la ley simple que regulará en detalle lo dispuesto por la reforma constitucional.

33 Senado de la República, Informe de la Comisión de Constitución, Legislación, Justicia y Reglamento, Reforma a la Constitución Política de la República de 1980, noviembre de 2001, p. 339. 


\section{Se incorpora el control preventivo obligatorio de la constitucionalidad de los tratados que traten sobre materias de ley orgánica constitucional.}

7. Control preventivo obligatorio de constitucionalidad de los tratados internacionales.

La reforma incorpora el control preventivo obligatorio de la constitucionalidad de los tratados internacionales que versen sobre materias de ley orgánica constitucional (Art. $82 \mathrm{~N}^{\circ} 1$ ).

Esta modificación es coherente con aquella que se introduce al Art. $50 \mathrm{~N}^{\circ} 1$ en materia de quórum de aprobación de los tratados y deja a salvo la posibilidad de que tratándose de tratados que no versen sobre materias de ley orgánica constitucional pueda deducirse -como hasta ahora- una «cuestión de constitucionalidad» (Art. $82 \mathrm{~N}^{\circ} 2$ que pasa a ser $\mathrm{N}^{\circ} 3$ con la reforma), mientras el tratado se encuentra sometido a la aprobación del Congreso, como lo ha precisado el Tribunal Constitucional.

La doctrina ha admitido la viabilidad del control preventivo de constitucionalidad de los tratados internacionales por dos razones: a) preservar la supremacía constitucional y b) evitar la impugnación de los tratados una vez comprometida la volun- tad del Estado, lo que puede abrir el camino de su responsabilidad internacional al tenor del Art. 27 de la Convención de Viena, tal como lo ha hecho presente nuestro Tribunal Constitucional ${ }^{34}$.

Así, el referido control preventivo apunta, por un lado, a evitar que el Estado se comprometa internacionalmente en forma incompatible con su Constitución y, por otro, a posibilitar la reforma constitucional previa que permita la ratificación del tratado como lo contemplan expresamente las Constituciones de El Salvador (Art. 145), España (Art. 95.1) y Perú (Art. 57).

\section{LOS DESAFÍOS PENDIENTES}

Después del análisis realizado precedentemente, puede sostenerse que, en general, la reforma aprobada asume o corrige los vacíos e imperfecciones que había demostrado la normativa constitucional previa en materia de tratados. Sin embargo, pensamos que esta normativa aún puede ser perfeccionada con el objeto de favorecer la plena inserción de Chile en el mundo globalizado que nos caracteriza. Por lo tanto, sugerimos que el debate constitucional futuro se haga cargo de los siguientes aspectos:

1. Contemplar alguna disposición constitucional similar a las que existen en

34 En el fallo recaído en el examen de constitucionalidad del Convenio $\mathrm{N}^{\circ} 169$ de la OIT sobre Pueblos Indígenas y tribales en países independientes, expresó que «entraña particular gravedad para un Estado, en el ámbito internacional, la declaración de inconstitucionalidad de las normas de un tratado, por un órgano jurisdiccional interno, lo que obliga al intérprete a hacer todos los esfuerzos, dentro de lo permitido por la Ley Suprema, por encontrar una interpretación conciliatoria entre las normas de un tratado y los preceptos de la Constitución», Rol No 309, de 4 de agosto de 2000, considerando $3^{\circ}$. 
el derecho comparado, según las cuales la celebración de un tratado internacional incompatible con la Constitución exigirá previa reforma de esta. Cabe recordar, en este sentido, que la conclusión del Tribunal Constitucional, al examinar la constitucionalidad del Tratado de Roma -que dio origen a la Corte Penal Internacional-fue precisamente la de efectuar una reforma constitucional previa que permitiese ratificar el tratado, la que hasta la fecha se encuentra pendiente.

2. Aclarar el tema del rango normativo de los tratados internacionales sobre derechos humanos que ya ha sido zanjado por la mayoría de las Constituciones de última generación (Argentina (Art. 75 $\mathrm{N}^{\circ}$ 22), Colombia (Art. 93), Ecuador (Art. 163) y Guatemala (Art. 46).

3. Incluir una disposición que autorice la delegación de competencias en entidades supranacionales, que es inevitable dado los avances de los procesos de integración. Curiosamente, el Anteproyecto de la Comisión de Estudios de la Nueva Constitución -con una gran visión de futurohabía propuesto una norma según la cual «los tratados que pudieren conferir atribuciones o competencias a organismos de carácter supranacional, deberán ser aprobados en cada rama del Congreso por la mayoría absoluta de sus miembros en ejercicio y luego por el pueblo en un plebiscito» (Art. $56 \mathrm{~N}^{\circ} 19$ inciso $4^{\circ}$ ).
La moción de los senadores de la Alianza por Chile-que fue una de las que dio origen a la reforma constitucional del año 2005-había propuesto, entretanto, una norma según la cual «los tratados que acepten jurisdicción internacional o que modifiquen materias reguladas por la Constitución no podrán ser firmados por el presidente de la República si previamente no se han reformado las normas constitucionales pertinentes o autorizado específicamente la entrega de jurisdicción». Las indicaciones formuladas por el Poder Ejecutivo, no obstante, no se hicieron cargo de esta proposición ${ }^{35} \mathrm{y}$, en definitiva, no quedó incorporada a la Constitución una norma de esta naturaleza, tal como ocurrió con la iniciativa de la Comisión Ortúzar.

\section{Convendría incluir una disposición que autorizara la delegación de competencias en entidades supranacionales.}

4. Contemplar una referencia a principios de carácter constitucional que orienten las relaciones internacionales del Estado, como se incluye en las Constituciones de Argentina (Art. 27), Brasil, (Art. 4), Colombia (Arts. 226 y 227), Ecuador (Art. 4) y El Salvador (Art. 89). Cabe recordar que durante el debate sos-

35 El Director Jurídico de la Cancillería, Claudio Troncoso, solo planteó en el Senado que podría estudiarse una fórmula intermedia, consistente en «establecer esta norma, dejando expresa constancia en la historia de la ley que la voluntad del Constituyente es que mediante dicha disposición se permita expresamente que el Estado de Chile ratifique el Tratado de Roma sobre la Corte Penal Internacional, no siendo necesario, para estos efectos, otras reformas a la Constitución», Segundo Informe de la Comisión de Constitución, Legislación, Justicia y Reglamento del Senado, de 18 de marzo de 2003, p. 208. 
tenido al interior de la Comisión de Estudios de la Nueva Constitución Política se había propuesto una norma según la cual «Chile adhiere a los principios y normas universalmente aceptados del Derecho Internacional, y favorece los organismos mundiales y regionales para la paz y el desarrollo». Pese a que esta proposición no figuró en el Anteproyecto presentado al presidente de la República (se opuso
Alejandro Silva Bascuñan) nos parece una demostración de la óptica visionaria de la Comisión Ortúzar en el sentido ya explicado.

5. Agregar alguna norma relacionada con la forma en que las decisiones de entidades u organismos como de los tribunales internacionales puedan tener efecto en Chile, lo que, hasta hoy, abre tremendas interrogantes. 